Research Article

\title{
Fourth-Grade Primary School Students' Misconception on Greatest Common Factor and Least Common Multiple
}

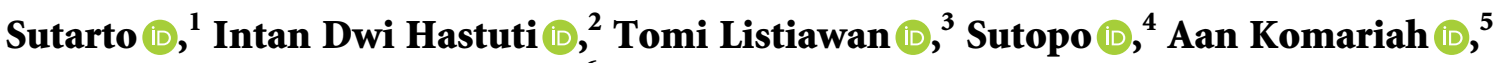 \\ and Mohammadreza Dabirnia iD ${ }^{6}$ \\ ${ }^{1}$ Mathematics Education, Faculty of Science, Engineering and Applied, Universitas Pendidikan Mandalika, Mataram, Indonesia \\ ${ }^{2}$ Elementary School Teacher Education, Faculty of Teacher Training and Education, Universitas Muhammadiyah Mataram, \\ Mataram, Indonesia \\ ${ }^{3}$ Department of Mathematics Education, Faculty of Social and Humaniora, Universitas Bhinneka PGRI, Tulungagung, Indonesia \\ ${ }^{4}$ Universitas Islam Negeri Sayyid Ali Rahmatullah Kota, Tulungagung, Indonesia \\ ${ }^{5}$ Educational Administration Department, Indonesia University of Education, Bandung, Indonesia \\ ${ }^{6}$ Department of Dramatic Literature, Tarbiat Modares University, Tehran, Iran
}

Correspondence should be addressed to Mohammadreza Dabirnia; gh_asse@yahoo.com

Received 25 August 2021; Accepted 20 September 2021; Published 8 October 2021

Academic Editor: Ehsan Namaziandost

Copyright $(92021$ Sutarto et al. This is an open access article distributed under the Creative Commons Attribution License, which permits unrestricted use, distribution, and reproduction in any medium, provided the original work is properly cited.

This study is aimed at determining students' misconceptions on the teaching material of the greatest common factor and least common multiple. The sample of this study consisted of 124 fourth-grade elementary school students in the academic year of 2019-2020 in areas of Mataram, West Lombok, North Lombok, and East Lombok at West Nusa Tenggara Province. The instrument of this study is a test covering five questions in the form of open questions. The data are analyzed based on the students' explanations while they answer the test. The students' wrong answers are grouped into categories. The interview activities are carried out for students who have a misconception. Then, researchers create a table of frequencies/presentations relating to each type of students' misconception. The results show that students experience misconceptions due to factors, including having a weak multiplication concept, having a weak prime number concept, determining the least common multiple of two numbers by multiplying the two numbers, and inability to distinguish between multiples and factors of a number. In light of the findings, a number of conclusions are obtained and several implications are put forward.

\section{Introduction}

The lowest common multiple and the biggest common factor are important materials that must be mastered by students at the fourth-grade primary schools in Indonesia. Factors and multiples are basic lessons of fractions. To simplify the fraction, students need to acquire the concept of the biggest common factor. To equalize the denominator in the fraction operation, students are required to master the concept of the lowest common multiple [1-4].

The characteristic of mathematics is that, in order to be successful in certain materials, students must master prerequisite materials. If a misconception happens on the prerequisite materials, it will give an effect of the misconception in the next teaching materials. One of the most crucial things in solving math problems is the acquisition of mathematical concepts. The implementation of mathematics learning in the school environment does not always have the expected success because of misconceptions [5].

The misconception is the initial concept of incompatibility scientifically agreed upon by the expert with the concept of knowledge brought by students [6-10]. Misconceptions can also be interpreted as differences in basic perceptions between students and experts, so it causes students' systematically incorrect understanding [11-13]. Therefore, it can be concluded that the misconception is a mismatch in understanding concepts between students and experts. 
Mathematics teaching-learning is interrelated instruction between a concept and the previous concept. If students are not able to assimilate and accommodate the relationship between these concepts, they will make continuous mistakes. Students create new concepts using their previous knowledge. The instruction of the lowest common multiple and the biggest common factor regardless of students' experience and the absence of teaching aids will generate misconceptions.

Based on the results of the study, students' misconceptions on teaching materials of the biggest common factors and the lowest common multiple are caused by several factors, namely, the failure of students to understand the basic concepts of prime numbers, factors, and multiples [14-18]. Students' misconceptions on the lowest common multiple and the biggest common factor occur because students are confused about distinguishing the least common multiple from the greatest common factor $[19,20]$.

Students' misconceptions occur continuously because students have been taught only how to find the lowest common multiple and the biggest common factor. In addition, students are not taught the meaning or basic understanding of the lowest common multiple and the greatest common factor. Several effective methods can be used to determine the lowest common multiple and the biggest common factor, one of which is the prime factorization method using the factor tree [21-23]. Students apply this factor tree method without learning what the underlying reasons are in that the lowest prime factor must be used first as a numeric divisor. Even when using the prime factorization method to determine the lowest common multiple, students are directed to find the biggest rank while the greatest common factor is directed to find the lowest rank. Students do not have advanced thinking regarding the procedure of applying the factor tree method, and it is not clear whether the students really understand the concept that underlies the method. In this case, students are more likely to focus on procedural skills without a good concept mastery. The study in [24] added that a lot of schools did not even teach the basic meaning of least common multiple and greatest common factor.

Based on the results of observations by distributing questions about real life, namely, "Mother has 18 oranges and 12 apples. The mother wants to put 18 oranges and 12 apples into a plastic bag, provided that each plastic bag contains the same amount of oranges and also each plastic bag contains the same number of apples. How many plastic bags are needed by the mother?" This question requires students to apply the concept of the biggest common denominator. From the observations, findings show that only $10 \%$ of students answered correctly, $60 \%$ of students answered wrongly, and $30 \%$ of students did not answer. This shows that students can only associate the question with the lowest common multiple or the greatest common factor if the problem formulation is clearly stated when answering a question. However, when they are faced with a problem without clearly stating the use of the lowest common multiple and the greatest common factor, students are unable to relate the question to the term of the greatest common factor due to lack of understanding.
Having a low multiplication concept is one of the reasons why students at the primary school experience misconceptions of the multiplication material. Moreover, if students are asked to determine the multiple of a number whose value is large, most students are not careful in solving it. Basically, the prerequisite material for multiples is the multiplication material. In other words, because students master the concept of multiples, the concept of multiplication should be strengthened.

The students' misconceptions on the material of the lowest common multiple and the greatest common factor occur because of the students' weakness in the concept of prime numbers. Most students do not understand the concept of prime numbers. When asked to determine the prime number between 8 and 25, most students solve the problem by finding a multiple of 8 so that the results are 8 , 16 , and 24 .

The students' misconception also comes from the assumption that to determine the lowest common multiple of two numbers is to multiply the two numbers. When students are asked in an opened question whether 8 is the lowest common multiple of 2 and 4, most students answer that 8 is the lowest common multiple of 2 and 4 because 2 times 4 is 8 .

The students' misconceptions also occur because they cannot distinguish between multiples and factors of a number. When they are asked to determine the common factor of 12 and 18, the first step that students do is to determine the factor of 12 .

The students' misconceptions are necessary to be further analyzed so that the causes can be identified and in the future teachers can plan instructional methods directing aspects of students' conceptual understanding. The teachers are to create learning experiences to develop students' understanding of concepts, ideas, and applications as an integrated whole process of learning mathematics $[25,26]$. The questions proposed in this study are different from previous studies, where this study formulates open-ended questions that direct students to explain how they solve each question and solve it. Previous research examines more about the analysis of students' errors in solving the problem of lowest common multiple and greatest common factor. The students' mistakes in solving the smallest common multiple problems and the greatest common factor can be explored if teachers can first see the extent of students' basic concept mastery such as the concept of prime numbers, multiples, factors, biggest common factor, and lowest common multiple. This study is expected to provide detailed information about students' thinking ways. By analyzing misconceptions at the primary school level, problem-solving can be immediately done effectively so that these misconceptions do not carry over to the next level of education.

1.1. Research Goal. This study is aimed at determining students' misconceptions on prime numbers, factors, multiples, biggest common factors, and lowest common multiple at the fourth-grade primary schools in West Nusa Tenggara, Indonesia. 
1.1.1. Research Problems. The main problem of this study is "what misconceptions are done by the 4 th-grade students regarding the material of the lowest common multiple and the biggest common factor?" The subproblems of this study are as follows:

(1) What misconceptions occur to the fourth-grade students regarding prime numbers?

(2) What misconceptions occur to the fourth-grade students regarding factors?

(3) What misconceptions occur to the fourth-grade students regarding multiples?

(4) What misconceptions occur to the fourth-grade students regarding the biggest common factor?

(5) What misconceptions occur to the fourth-grade students regarding the lowest group multiple?

\section{Methodology}

2.1. Research Design. This study aims to uncover the misconceptions of the fourth-grade students about the lowest common multiple and biggest common factor and to find out more about misconception issues. This study is qualitative research using the case study method. The case study method is defined as the determination of the investigation status and in-depth examination from a certain situation $[27,28]$. This case study method is used when it is necessary to examine the situation as a whole and comprehensively [29]. The case study method was also used to determine the types of students' misconceptions about the lowest common multiple and the greatest common factor and to investigate these misconceptions in depth [28].

2.2. Research Instruments. The instrument of collecting data in this study is an interview in the form of 12 open-ended questions to investigate students' understanding of prime numbers, factors, multiples, greatest common factors, and least common multiples. In the first question, students are asked to determine the factor of a number along with the completion process. The second question leads students to determine the multiple of a number and the process of solving it. The third and fourth questions direct students to determine the prime numbers and prime factors of a number. The fifth question leads students to determine true or false statements about the multiple of a number and is accompanied by the reasons why they chose the right or wrong answer. The sixth question leads students to determine the greatest common factor of a number. The students' answers and explanations are then checked and whether there are misconceptions or not is determined. Before the questions were given to the fourth-grade students, the question items were validated first by 5 experts of mathematics education and elementary school teachers. It is worth mentioning that the experts were 5 professors who taught mathematics for more than 20 years and were completely familiar with the greatest common factor and least common multiple.
2.3. Research Sample. The sample of this study consisted of 124 fourth-grade primary school students in the academic year of 2019-2020 in areas of Mataram, West Lombok, North Lombok, and East Lombok provinces at West Nusa Tenggara, Indonesia. The sampling method was random. In this sampling method, the probability of selecting each group is equal to one another [30]. The distribution of students who are participating in the study according to gender is presented in Table 1.

Table 1 shows that the percentage of male students who participated in this study was $48 \%$, and the percentage of female students who participated in this study was $52 \%$.

2.4. Data Analysis. Students' answers are checked into three categories, namely, true, false, and blank (not answered) for each question. Students' misconceptions are determined by looking at the answers they gave, the explanations they made, and interviews with subjects who represent each type of misconception. The researchers divided the misconceptions into several categories based on the results of examining all students' answers. In data analysis, each student's response is coded by all the researchers independently. The intercoder reliability was calculated $(r=0.98)$ to ensure the credibility of the findings. The data analysis technique employs descriptive statistical analysis (frequency/percentage) obtained from the test results. The analysis is carried out separately for each question. Examples of misconceptions for each question are also presented and shown in tables.

\section{Findings and Discussion}

In this section, the analysis of the students' answers to each question is described. The analysis is carried out separately for each question. The following sections show the results of the analysis of misconceptions for each question.

3.1. Analysis Results of Students' Misconception for Question 1. The first question is about the concept of factors. In this question, students are asked to determine the factor of a number as well as explain the finishing process. The first question of the test is shown in Figure 1.

The distribution of students' answers to the first question is presented in Table 2 .

Table 2 provides a visual presentation of the percentage of students who answered incorrectly in point $a$ which is $40 \%$. The percentage of students who answered incorrectly on point $b$ is $48 \%$ and point $c$ is $52 \%$. In other words, the students' errors in points $a, b$, and $c$ have increased. The types of misconceptions and examples of students' answers to question number 1 are given in Table 3 .

Based on the results of students' answers and interviews, the first misconception is that when they are asked to determine the factor of a number, they answer by looking for its multiples. There are students who answered that the multiples of 12 were 12, 24, 36, 48, 60, and so on. From the results of the interview, it was revealed that students have difficulties distinguishing between multiples and factors. The second misconception is that when students are asked to 
TABLE 1: Distribution of students according to gender.

\begin{tabular}{lcc}
\hline Gender & Frequency & Percentage \\
\hline Male & 60 & 48 \\
Female & 64 & 52 \\
Total & 124 & 100 \\
\hline
\end{tabular}

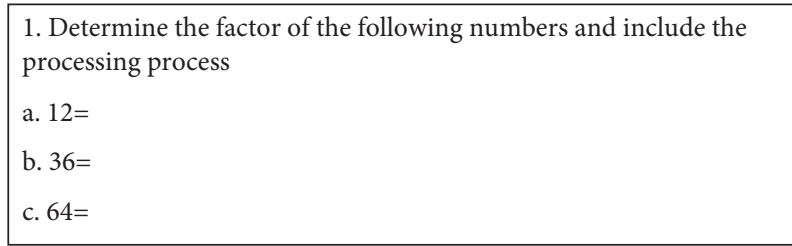

Figure 1: Questions of factor concepts.

TABle 2: Distribution of students' answer to question 1.

\begin{tabular}{|c|c|c|c|c|c|c|}
\hline \multirow{2}{*}{ Evaluation } & \multicolumn{2}{|c|}{$\mathrm{a}$} & \multicolumn{2}{|c|}{$\mathrm{b}$} & \multicolumn{2}{|c|}{$\mathrm{c}$} \\
\hline & $\mathrm{f}$ & $\%$ & $\mathrm{f}$ & $\%$ & $\mathrm{f}$ & $\%$ \\
\hline Correct & 71 & 57 & 58 & 47 & 52 & 42 \\
\hline Incorrect & 50 & 40 & 60 & 48 & 64 & 52 \\
\hline No answer & 3 & 3 & 6 & 5 & 8 & 6 \\
\hline Total & 124 & 100 & 124 & 100 & 124 & 100 \\
\hline
\end{tabular}

TABLE 3: Students' misconception in question 1 and examples of students' answer.

Determining factors from a number through seeking for its multiples

a. $12=$

$12 / 24 / 36 / 48 / 60 / 72 / 84$

1. Determine the factor of the following numbers and include the processing process

b. $36=$

Seeing factors as multiples from two numbers under 10

$4 / 6 / 9$

1. Determine the factor of the following numbers and include the processing process

c. $64=$

$8 / 7 / 9$

determine the factors, they only focused on multiplying two numbers under 10 . They answered 4,6 , and 9 , when students are asked to determine a factor of 36 . Thus, they only focus on multiplying two numbers under 10 . It should be noted that 18 and 2 are factors of 36 and 12 and 3 are factors of 36. From the results of the interviews, it was revealed that the concept of student multiplication is still low; especially, for multiples above 10, they still face difficulties. 
3.2. Analysis Results of Students' Misconception for Question 2. In question 2, students are asked to determine multiples of 5 , which are less than 50 , and those of 12 , which are less than 100 , along with the finishing process. Question 2 is presented in Figure 2.

The distribution of students' answers to question 2 can be presented in Table 4 .

$38 \%$ of students answered incorrectly for the question in point (a), and $48 \%$ of students answered incorrectly for the question in point $(b)$. Student misconceptions also occur in multiples of materials. The types of misconceptions and examples of students' answers to question 2 are shown in Table 5.

Based on the results of students' answers and interviews with students to find multiples of a number, students multiply a number consistently. Students answer that multiples of 5 are 5,25, and 125. Students assume that to find the multiples of 5 is to multiply the number 5 by 5 so that it produces 25 and then multiply 25 by 5 so that the result is 125. Actually, to determine the multiple of a number, students can multiply the number with the original number sequentially. More specifically, interviews revealed that students are also weak in multiplication, especially multiplication above 10 . This is seen from the student's answer when answering that multiples of 12 are 12, 24, 31, and 88 . Students are also confused by the term "less than" on question number 2 .

3.3. Analysis Results of Students' Misconception for Question 3. In question 3, students are asked to determine prime numbers. Question 3 can be presented in Figure 3.

The distribution of students' answers to accomplishing question 3 is presented in Table 6.

Table 6 shows that $40 \%$ of students answered incorrectly to question number 3 and $28 \%$ of students did not answer question 3. Students' misconceptions in question 3 are given in Table 7, along with examples of student answers. From the results of the analysis of students' answers and interviews, it was found that there are misconceptions that are described in detail in Table 7.

Based on the results of students' answers and interviews, the finding shows that students considered prime numbers as composite numbers. When answering prime numbers between 8 and 25, students finished by looking for a factor of 8. This fact happens because the students' concept of prime numbers is still very low. Prime numbers are natural numbers that have exactly two factors, namely, one and itself.

3.4. Analysis Results of Students' Misconception for Question 4. In question 4 , students are asked to determine the prime factors of 20 and 42 along with the completing process. Question 4 can be seen in Figure 4.

The distribution of students' answers to accomplishing question 4 is presented in Table 8.

Based on Table 8, the data showed that $44 \%$ of students answered incorrectly and $24 \%$ of students did not answer.

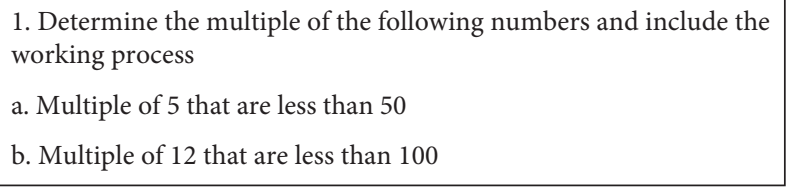

FIGURE 2: Questions of the multiple concept.

TABLE 4: Distribution of students' answer to question 2.

\begin{tabular}{lcccc}
\hline Evaluation & \multicolumn{2}{c}{ a } & & \multicolumn{3}{c}{ b } \\
& $\mathrm{F}$ & $\%$ & $\mathrm{f}$ & $\%$ \\
\hline Correct & 70 & 56 & 56 & 46 \\
Incorrect & 47 & 38 & 60 & 48 \\
No answer & 7 & 6 & 8 & 6 \\
Total & 124 & 100 & 124 & 100 \\
\hline
\end{tabular}

After analyzing student answers and conducting interviews, misconceptions are found as described in Table 9.

Based on the results of student answers and interviews, the data show that there are several student misconceptions when determining the prime factors. First, students could not identify all prime factors. This misconception occurs because the students' concept relating to prime numbers is still weak. When students are asked to determine prime factors of 20 and 42 , students can determine only factors from 20 and 42; in turn, students cannot identify the primacy. Students do not fully understand the definition of prime numbers. Second, students cannot distinguish between prime factors and factors. Third, students use the factor tree method, but the number sought for the prime factor is not divided by the smallest prime number. Based on the results of the interview, the data show that the students do not find the smallest prime number, and they assume that 6 is the smallest prime number that could divide 42 .

\subsection{Analysis Results of Students' Misconception for Question 5.} In question 5, students are given open-ended questions and are asked to determine whether they are true or false in relation to 3 statements of 8 . Question 5 can be seen in Figure 5.

The distribution of students' answers to accomplishing question 5 is presented in Table 10.

Based on Table 10, the data show that $58 \%$ of students answered incorrectly to question 5 in point $a, 52 \%$ of students answered incorrectly to the question in point $b$, and $48 \%$ of students answered incorrectly to question in point $c$. In addition, the percentage of students who do not answer the question in point $a$ is $2 \%$, point $b$ is $4 \%$, and item $b$ is $2 \%$. In more detail, the misconceptions made by students in solving question 5 can be seen in Table 11.

Based on the results of students' answers and interviews, the finding shows that there are several student misconceptions when answering question 5 . First, students determine the least common multiple of two numbers by multiplying the two numbers. Students correctly assume that 8 is a multiple of 2 and 4 as 2 multiplied by 4 becomes 8 . The second misconception is that the students choose the largest 
TABLE 5: Students misconception in question 2 and examples of students' answer.

\begin{tabular}{l|l|}
\hline Misconception types & Students answer sample \\
\hline Multiplying a number consistently & aultiple of 5 that are less than 50 \\
\hline & b. Multiple of 12 that are less than 100 \\
\hline Low multiple concept & $12,24,31,38,45,52,62,74,82,88$ \\
\hline
\end{tabular}

3. Find the prime numbers between 8 and 25

FIgURE 3: Question 3.

TABLE 6: Distribution of students' answer to question 3.

\begin{tabular}{lcc}
\hline Evaluation & f & a \\
\hline Correct & 40 & $\%$ \\
Incorrect & 49 & 32 \\
No answer & 35 & 40 \\
Total & 124 & 28 \\
\hline
\end{tabular}

TABLE 7: Students' misconception in question 3 and examples of students answer.

\begin{tabular}{lr}
\hline Misconception types & Students' answer sample \\
\hline Considering prime numbers as composite numbers & 3. Find the prime numbers between 8 and 25 \\
\hline & $8(1,2,4,8) ; 25(1,5,25)$ \\
\hline
\end{tabular}

3. Find the prime factors of 20 and 42

Figure 4: Question 4.

TABLE 8: Distribution of students' answer to question 4.

\begin{tabular}{lcc}
\hline Evaluation & f & a \\
\hline Correct & 40 & 32 \\
Incorrect & 54 & 44 \\
No answer & 30 & 24 \\
Total & 124 & 100 \\
\hline
\end{tabular}

number that becomes the least common multiple of two numbers. At the first step, the student properly identified the multiples of 3 and 6 , but at the next step, the student determined the largest number of 18 as the least common multiple. Based on the results of the interview, this misconception reveals that the students are successful in the first and second steps, namely, determining the multiple of each number and determining the common. In the last step, students fail where they choose the largest number.

3.6. Analysis Results of Students' Misconception for Question 6. In question 6, students are asked to determine the greatest common factor. Question 6 can be seen in Figure 6 . 
TABLE 9: Students misconception in question 4 and its answer category.

\begin{tabular}{l|r|}
\hline Misconception types & \multicolumn{1}{c}{ Students answer sample } \\
\hline Cannot identify all prime factors & 3. Find the prime numbers between 20 and 42 \\
\hline & $20(1,2,10,20) ; 42(1,2,21,42)$ \\
\hline & 3 . Find the prime numbers between 20 and 42 \\
\hline
\end{tabular}

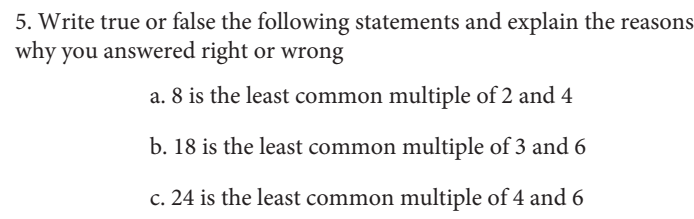

Figure 5: Question 5.

Table 10: Distribution of students' answer to question 5.

\begin{tabular}{|c|c|c|c|c|c|c|}
\hline \multirow{2}{*}{ Evaluation } & \multicolumn{2}{|c|}{$\mathrm{a}$} & \multicolumn{2}{|c|}{$\mathrm{b}$} & \multicolumn{2}{|c|}{ c } \\
\hline & $\mathrm{f}$ & $\%$ & $\mathrm{f}$ & $\%$ & $\mathrm{f}$ & $\%$ \\
\hline Correct & 50 & 40 & 55 & 44 & 62 & 50 \\
\hline Incorrect & 72 & 58 & 65 & 52 & 60 & 48 \\
\hline No answer & 2 & 2 & 4 & 4 & 2 & 2 \\
\hline Total & 124 & 100 & 124 & 100 & 124 & 100 \\
\hline
\end{tabular}

TABLE 11: Students misconception in question 5 and its answer category.

\begin{tabular}{l} 
Misconception types \\
Determining the least common multiple from two numbers by multiplying the two numbers \\
Choosing the greatest numbers \\
b. 18 is the least common multiple of 3 and 6 \\
Because $3 \times 6=18$ \\
\hline
\end{tabular}

6. Find the Greatest Common Factor from the following two numbers

$$
\begin{aligned}
& \text { a. } 12 \text { dan } 18 \\
& \text { b. } 32 \text { dan } 48
\end{aligned}
$$

Figure 6: Question 6. 
TABle 12: Distribution of students' answer to question 6.

\begin{tabular}{|c|c|c|c|c|}
\hline \multirow{2}{*}{ Evaluation } & \multicolumn{2}{|c|}{$\mathrm{a}$} & \multicolumn{2}{|c|}{$\mathrm{b}$} \\
\hline & $\mathrm{F}$ & $\%$ & $\mathrm{f}$ & $\%$ \\
\hline Correct & 94 & 76 & 85 & 69 \\
\hline Incorrect & 25 & 20 & 32 & 26 \\
\hline No answer & 5 & 4 & 7 & 5 \\
\hline Total & 124 & 100 & 124 & 100 \\
\hline
\end{tabular}

TABLE 13: Students misconception in question 6 and its answer category.

\begin{tabular}{|c|c|}
\hline Misconception types & Students answer sample \\
\hline \multirow{3}{*}{ Looking for number factors by determining its multiples } & $\begin{array}{l}\text { 6. Find the Greatest Common Factor from the following two } \\
\text { numbers } \\
\text { a. } 12 \text { dan } 18\end{array}$ \\
\hline & $\begin{array}{c}12=12,24,36,48,60,72 \\
18=18,36,54\end{array}$ \\
\hline & $\begin{array}{l}\text { 6. Find the Greatest Common Factor from the } \\
\text { following two numbers } \\
\qquad \begin{array}{l}\text { a. } 12 \text { dan } 18 \\
\text { b. } 32 \text { dan } 48\end{array}\end{array}$ \\
\hline Looking for the same factors with the largest rank & $\begin{array}{c}12=2,4,2,3 \\
18=2,9,3,3 \\
32=2,16,2,8,2,4,2,2 \\
48=2,24,2,12,2,6,2,3\end{array}$ \\
\hline
\end{tabular}

Based on Table 12, the data show that $20 \%$ of students answered incorrectly for question 6 in point $a$ and $26 \%$ of students answered incorrectly for question in point $b$. In addition, the percentage of students who did not answer the question in point $a$ is $4 \%$ and point $b$ is $5 \%$. In more detail, the misconceptions made by students in solving question number 6 can be seen in Table 13 .

Based on the results of students' answers and interviews, the data show that there are several students' misconceptions when answering question 6 . First, the students look for the number factors by determining their multiples. Based on the results of the interview, this misconception occurs because students cannot distinguish between the concept of factors and multiples. Second, a misconception occurs to find an equal number to the greatest rank. Based on the results of the interview, this misconception occurs because students think that, after looking for the prime factorization, to determine the biggest common factor is to look for the same factor with the largest rank.

\section{Discussion, Conclusion, and Recommendation}

There are several students' misconceptions in completing the least common multiple, the biggest common factor, and the influential factors. In question 1 relating to determining factors, it appears that students experience misconceptions. Regarding students' answers to question 1 relating to determining the factors of a number, there are two types of misconceptions. The first misconception is because students see the factor as the multiplication of two numbers under ten only. Based on the results of the interview, it was revealed that the cause of this misconception is that students' multiplication concept is still low, especially multiplication above 10. When large numbers are involved, students have difficulties determining the factors so that the percentage of students' errors increased in item $c$. To minimize this misunderstanding, the concept of student multiplication needs to be strengthened especially for multiplication above 
10. The second misconception is that students determine the factor of a number by finding its multiples. The cause of this misconception is that students feel difficult to distinguish between multiples and factors. If the concept of factors is well understood, students' misconceptions about the common factor will not occur. This finding is consistent with Mohyuddin and Khalil's research which revealed that a considerable number of students lack clarity that 1 is the factor of all numbers and they mixed factors with multiples [8].

Student misconceptions also occur when students solve question 2 regarding determining the multiple of a number. From the results of the student work on question 2, there are two types of multiple misconceptions. The first misconception is multiplying by a consistent number. Based on the results of the interview, students are low in understanding the definition of multiples in question 2a. When asked to determine the multiple of 5, students answer 5, 25, and 125. From this task, the data show that students determine the next number by multiplying the previous number by 5 . It is supposed to determine the multiple of a number, and students can multiply the number with the original number sequentially. The second misconception is the misconception of the concept of multiplication, especially if it involves multiplying large numbers. To correct students' misconceptions regarding multiples, the first step that must be taken is to strengthen the concept of multiplication, especially the concept of multiplication 1-10, and give tricks to teach multiplication above 10 for students.

Student misconceptions also occur when students complete question 3 related to prime numbers. The percentage of student misconceptions in this section reached $48 \%$. The first misconception is to think of prime numbers as composite numbers. Based on the results of the interview, students are still low in understanding the definition of prime numbers. Children construct erroneous rules without reference to the conceptual content or the meaning of arithmetic [8].

In question 4, relating to prime factors, students also experience misconceptions. First, students cannot identify all prime factors. This misconception occurs because the students' concept regarding prime numbers is low. Students do not fully understand the definition of prime numbers. Second, students cannot distinguish between prime factors and factors. Third, students use the factor tree method, but the number looking for the prime factor is not divided by the smallest prime number. The misconception that occurs in question 4 is because there are several related concept sequences that fail to be understood properly. Students fail to understand the concepts of factors and prime numbers. Question 4 relates to questions 1 and 3. If students experience misconceptions in question 1, students will fail to answer question 4 correctly. To understand the concept of prime factors, students must understand the concept of factors and the concept of prime numbers, respectively $[17,19]$.

Some misconceptions also occur when students answer question 5. The first misconception is that students determine the least common multiple of two numbers by multiplying the two numbers. The second misconception is that students choose the largest number, which becomes the least common multiple of two numbers. Based on the results of the interview, students are successful in the first and second steps, namely, determining the multiple of each number and determining the association. Still, in the last step, the students failed, where they chose the largest number as the lowest common multiple. The difficulties in understanding the concepts of least common multiple are based on the teaching practices at the formal level that are often regarded as procedural and manipulative $[8,17]$.

Based on the results of students' answers and interviews, the findings show that there are several students' misconceptions when answering question 6. First, the students looked for the number factors by determining their multiples. Based on the results of the interview, this misconception occurs because students cannot distinguish between the concept of factors and multiples. When listing the numbers that are a factor of 12 , the answer is that factor 12 is $12,24,36$, and so on. The second misconception is to look for equal prime factors to the greatest rank. Based on the results of the interview, this misconception occurs because students think that, after looking for the prime factorization, to determine the biggest common factor is to look for the same factor with the largest rank. The student expressed that they were using the shortcut method without prior learning to the reason why the lowest prime factor needed to be used first as the divisor for the numbers. To make the student know how to use these methods of prime, there was no afterthought towards the answer or any discussions regarding it, and it was unclear whether the students really understood the concept that underlies the operation [19].

Based on the findings from the research results, the following suggestions are distributed: (1) In learning mathematics relating to the materials of the least common multiples and the greatest common factor, the most important is the basic concepts in accordance with prime numbers, factors, and multiples that must be strengthened first. (2) Instruction should be supported with concrete material so that there are no misconceptions about the concept of the least common multiple and the greatest common factor. (3) Not only is instruction emphasized on the procedural aspects through the factor tree, but also students need to emphasize the meaning. (4) Instruction should be done by paying attention to the difference in meaning between multiples and factors.

During the time of this study, the researcher faced some drawbacks. Due to time limitation, only 124 participants were included in this research. The study was limited to Indonesian learners; it can be conducted in other contexts. During conducting the present study, some suggestions came across the researcher's mind. The first suggestion for future studies is to include more participants to get more reliable results. The second suggestion is that the next researches are recommended to conduct similar topics in other geographical areas. Finally, since the sample included in this study was of almost equal number of male and female participants, future researchers are recommended to consider the responses and misconceptions in terms of the students' gender. 
The results of this study help the learners to pose various strategies and to plan and decide the best technique to overcome real-life problems. With the teachers' guidance, the learners related their techniques to their previous knowledge and comprehension. Thus, these actions help the learners to be more aware of their real-life surroundings; they might relate the problem to the greatest common factor and least common multiple and develop their metacognitive process to think creatively.

\section{Data Availability}

The data that support the findings of this study are available from the corresponding author upon reasonable request.

\section{Conflicts of Interest}

The authors declare that they have no conflicts of interest.

\section{References}

[1] H. -J. Lee and I. Boyadzhiev, "Underprepared college students' understanding of and misconceptions with fractions," International Electronic Journal of Mathematics Education, vol. 15, no. 3, Article ID em0583, 2020.

[2] O. Meric and I. Yakin, "How do pre-service mathematics teachers organize information sources in the WebQuest?" European Journal of Educational Research, vol. 91, pp. 237256, 2021.

[3] G. L. Musser, W. F. Burger, and B. E. Peterson, Mathematics for Elementary Teachers, John Wiley \& Sons, Inc, Hoboken, NJ, USA, 2011.

[4] K. Wahyu, S. M. Amin, and A. Lukito, "Motivation cards to support students' understanding on fraction division," International Journal on Emerging Mathematics Education, vol. 1, no. 1, pp. 99-120, 2017.

[5] S. Lin, X. Wang, L. Chen, J. Zhu, and Y. Wang, "The relationship between student teachers' professional identity and anxiety: the moderating role of campus pressure," Open Journal of Social Sciences, vol. 5, no. 6, pp. 214-223, 2017.

[6] I. S. Caleon and M. Subramaniam, "Do students know what they know and what they don't know? using a four-tier diagnostic test to assess the nature of students' alternative conceptions," Research in Science Education, vol. 40, no. 1, pp. 313-337, 2010.

[7] I. Idehen, "Large-scale generation and validation of synthetic PMU data," IEEE Transactions on Smart Grid, vol. 11, no. 5, pp. 4290-4298, 2020.

[8] R. G. Mohyuddin and U. Khalil, "Misconceptions of students in learning mathematics at primary level," Bulletin of Education and Research, vol. 38, no. 1, pp. 133-162, 2016.

[9] H. Pesman and A. Eryilmaz, "Development of a three-tier test to assess misconceptions about simple electric circuits," The Journal of Educational Research, vol. 103, no. 1, pp. 208-222, 2010.

[10] E. J. Sintema and J. M. Marban, "Pre-service teachers' knowledge of identifying and clearing pupils' misconceptions about inverse and composite functions via vignettes," Eurasia Journal of Mathematics, Science and Technology Education, vol. 17, no. 1, pp. 19-30, 2021.

[11] P. Malambo, "Implicit misconceptions in prospective mathematics teachers' reasoning about trigonometric concepts,"
Contemporary Mathematics and Science Education, vol. 2, no. 2, pp. 1-23, 2021.

[12] J. Noonan, "An affinity for learning: teacher identity and powerful professional development," Journal of Teacher Education, vol. 3, no. 1, pp. 1-12, 2018.

[13] J. P. Smith, A. A. diSessa, and J. Roschelle, "Misconceptions reconceived: a constructivist analysis of knowledge in transition," The Journal of Learning Sciences, vol. 3, no. 2, pp. 115-163, 1993.

[14] A. Jansen and C. Hohensee, "Examining and elaborating upon the nature of elementary prospective teachers' conceptions of partitive division with fractions," Journal of Mathematics Teacher Education, vol. 2, no. 3, pp. 1-20, 2015.

[15] M. Khalid and Z. Embong, "Sources and possible causes of errors and misconceptions in operations of integers," International Electronic Journal of Mathematics Education, vol. 15, no. 2, pp. 5-68, 2020.

[16] A. A. A. Mohammed and M. M. Harwell, "Data analysis: strengthening inferences in quantitative education studies conducted by novice researchers," Educational Sciences: Theory and Practice, vol. 20, no. 1, pp. 59-78, 2020.

[17] S. Triyani, R. I. I. Putri, and D. Darmawijoyo, "Supporting student's ability in understanding least common multiple (LCM) concept using storytelling," Journal on Mathematics Education, vol. 3, no. 2, pp. 151-164, 2012.

[18] E. Unaenah, A. Oktavia, N. Indah, and N. Hadisumarno, "Miskonsepsi materi tentang FPB dan KPK pada siswa SD di kelas tinggi," Jurnal Pendidikan Dan Ilmu Sosial, vol. 2, no. 2, pp. 276-282, 2020.

[19] N. L. A. Halim, H. C. Li, M. Shahrill, and R. C. I. Prahmana, "Teaching strategies in the learning of highest common factor and lowest common multiple," Journal of Physics: Conference Series, vol. 943, no. 1, pp. 1-9, 2017.

[20] U. Tugba, "Phenomenological study about mathematics teaching anxiety in the context of professional identity," European Journal of Educational Research, vol. 93, pp. 301318, 2021.

[21] S. N. N. Putri Manjanai and M. Shahrill, "Introducing the flipped classroom strategy in the learning of year nine factorization," The International Journal of Interdisciplinary Educational Studies, vol. 11, no. 4, pp. 35-55, 2016.

[22] J. Sharp and R. M. Welder, "Reveal limitations through fraction division problem posing," Mathematics Teaching in the Middle School, vol. 19, no. 9, pp. 540-547, 2014.

[23] I. Zych, "Research in educational sciences: its importance and quality standards for evidence based educational practice," Kuram ve Uygulamada Egitim Bilimleri, vol. 20, no. 1, pp. 1-4, 2020.

[24] J. Suffolk, "Making the teaching of mathematics more effective," in Proceedings of the Redesigning Pedagogy: Culture, Knowledge and Understanding Conference, Singapore, 2007.

[25] A. Betul and B. Aybek, "The effects of subject-based critical thinking education in mathematics on students' critical thinking skills and virtues," European Journal of Educational Research, vol. 92, pp. 99-119, 2020.

[26] M. Chong, M. Shahrill, and H. L. Li, "The integration of a problem-solving framework for Brunei high school mathematics curriculum in increasing student's affective competency," Journal on Mathematics Education, vol. 10, pp. 215-228, 2019.

[27] R. C. Bogdan and S. K. Biklen, Qualitative Research for Education: An Introduction to Theory and Methods, Pearson Education, Inc, London, UK, 2007. 
[28] I. D. Hastuti, Surahmat, and Sutarto, "Development of collaborative inquiry-based learning model to improve elementary school students 'metacognitive ability," International Journal of Scientific and Technology Research, vol. 9, no. 2, pp. 1240-1247, 2020.

[29] J. R. Feagin, A. M. Orum, and G. Sjoberg, A Case for the Case Study, University of North Carolina Press, Chapel Hill, NC, USA, 1991.

[30] S. Çepni, Introduction to Research and Project Studies, Celepler Printing, Trabzon, Turkey, 2010. 